\title{
Endoplasmic reticulum stress in hepatic steatosis and inflammatory bowel diseases
}

\author{
Beichu Guo ${ }^{1,2}$ * and Zihai $\mathrm{Li}^{1,2}$ * \\ 'Department of Microbiology and Immunology, Medical University of South Carolina, Charleston, SC, USA \\ ${ }^{2}$ Hollings Cancer Center, Medical University of South Carolina, Charleston, SC, USA
}

\section{Edited by:}

Kezhong Zhang, Wayne State

University, USA

\section{Reviewed by:}

Utpal Pal, University of Maryland, USA Guohui Wang, Houston Methodist Hospital, USA

\section{*Correspondence:}

Zihai Li and Beichu Guo, Department of Microbiology and Immunology and Hollings Cancer Center, Medical

University of South Carolina, HO-612F, Charleston, SC, USA

e-mail: zihai@musc.edu;

guobe@musc.edu
As an adaptive response to the overloading with misfolded proteins in the endoplasmic reticulum (ER), ER stress plays critical roles in maintaining protein homeostasis in the secretory pathway to avoid damage to the host. Such a conserved mechanism is accomplished through three well-orchestrated pathways known collectively as unfolded protein response (UPR). Persistent and pathological ER stress has been implicated in a variety of diseases in metabolic, inflammatory, and malignant conditions. Furthermore, ER stress is directly linked with inflammation through UPR pathways, which modulate transcriptional programs to induce the expression of inflammatory genes. Importantly, the inflammation induced by ER stress is directly responsible for the pathogenesis of metabolic and inflammatory diseases. In this review, we will discuss the potential signaling pathways connecting ER stress with inflammation. We will also depict the interplay between ER stress and inflammation in the pathogenesis of hepatic steatosis, inflammatory bowel diseases and colitis-associated colon cancer.

Keywords: ER stress, inflammation, hepatic steatosis, colitis, UPR, inflammasome, IRE1

\section{INTRODUCTION}

The endoplasmic reticulum (ER) is an intracellular organelle involving in folding of membrane and secreted proteins, synthesis of lipids and sterols, and maintenance of intracellular calcium homeostasis (Kleiner and Brunt, 2012; Milic and Stimac, 2012; Tuyama and Chang, 2012; Wierzbicki and Oben, 2012; Ibrahim et al., 2013). ER chaperones, such as glucose-regulated protein of $78 \mathrm{kDa}$ (GRP78) and $94 \mathrm{kDa}$ (GRP94, also termed as gp96) function as a quality control system that monitors newly synthesized proteins, and ensures only correctly folded proteins to be transported out of ER (Yang and Li, 2005; Yang et al., 2007; Zhang et al., 2011; Cnop et al., 2012; Chen etal., 2013; Lake et al., 2013). ER stress takes place when unfolded or misfolded proteins accumulate in the ER lumen. In response to stress conditions, ER initiates a series of unfolded protein response (UPR) signal transduction pathways, including inositol-requiring enzyme 1 (IRE1), doublestranded RNA-dependent protein kinase (PKR)-like ER kinase (PERK), and activating transcription factor-6 (ATF6) pathways, eventually, leading to changes in translational and transcriptional programs (Urano et al., 2000; McGuckin et al., 2010; Schroder and Sutcliffe, 2010; Hetz, 2012; Zha and Zhou, 2012). Cells that undergo constant ER stress include immune cells such as macrophages, plasma cells, and cells regulating metabolism such as hepatocytes, pancreatic $\beta$-cells, adipocytes, and mucosal epithelial cells. Those cells are sensitive to changes in the environments, protein traffic, and ER homeostasis (Ozcan et al., 2006; Eizirik and Cnop, 2010; McAlpine et al., 2010; Schroder and Sutcliffe, 2010; Staron et al., 2010; Ye et al., 2010; Ji et al., 2011; Pfaffenbach and Lee, 2011). While UPR is an adaptive response for cells to restore ER homeostasis, severe or prolonged ER stress leads to cell death and tissue damage. Accumulating evidence indicates that ER stress is involved in various diseases including neurodegenerative diseases, metabolic diseases, inflammatory diseases, cancer, and so on.

Recently, ER stress has been recognized to induce inflammation (McGuckin etal., 2010; Eri etal., 2011; Garg etal., 2012; Osorio et al., 2014; Shenderov et al., 2014). Interestingly, many ER stress-associated diseases also display inflammatory phenotypes (McGuckin et al., 2010; Eri et al., 2011; Garg et al., 2012; Larrain and Rinella, 2012; Petrasek et al., 2012; Szabo and Csak, 2012; Wood, 2012). Inflammatory cytokines released from stressed cells may function as alarming or danger signals to communicate with other cells or to recruit immune cells. While ER stressinduced inflammation is essential for tissue remodeling, it can cause tissue damage and contributes to the pathogenesis of many inflammatory and metabolic diseases (Eizirik and Cnop, 2010; McGuckin etal., 2010; Malhi and Kaufman, 2011; Cnop et al., 2012; Garg et al., 2012; Zha and Zhou, 2012). Inflammation can be induced directly by UPR pathways in stressed cells, or indirectly through interaction with innate immune cells. Induction of innate immunity is mediated by diverse families of Pattern Recognition Receptors (PRRs) that recognize molecular "signature" of the invading pathogens termed as pathogen associated molecular patterns (PAMPs; Takeuchi and Akira, 2010; Kawai and Akira, 2011). Additionally, innate immune cells can be activated by various endogenous ligands from damaged or dead cells. Toll-like receptors (TLRs) are a major family of PRRs mainly expressed by cells of the innate immune system. TLRs can initiate distinct innate immune responses through recruitment of different MyD88 adaptor family members. Currently, at least 13 TLRs have been cloned in mammals, and each receptor is involved in the recognition of a unique set of PAMPs. Studies from our group had demonstrated 
that GRP94 is a master molecular chaperone in the ER for TLRs. Our results show that the function of most TLRs is dependent on the integrity of GRP94 in the ER (Yang et al., 2007; Liu and Li, 2008). In addition to TLRs, most nucleated cells are capable of sensing and responding to pathogens inside the cytoplasm via intracellular receptors including NOD-like receptors (NLRs) or RIG-I-like receptor family members, which recognize bacteria or viruses, respectively.

TLR activation triggers the recruitment of MyD88 via the Tollinterleukin-1 receptor (TIR) domain, allowing for subsequent recruitment of IL-1R associated kinase (IRAK) and tumor necrosis factor (TNF) receptor associated factor 6 (TRAF6), which leads to the activation of both the NF- $\kappa \mathrm{B}$ and JNK pathways. In addition, TLRs are able to activate other signaling cascades including the PI3K, p38, and ERK pathways. Activation of these pathways leads to the expression of inflammatory cytokines such as TNF $\alpha$ and IL-6. Recent progress demonstrates that inflammasomes, signaling complexes essential for IL- $1 \beta$ production, are also involved in various inflammatory and metabolic diseases (Ting et al., 2010; Davis et al., 2011; Stienstra et al., 2011; Henao-Mejia et al., 2012a). Furthermore, pathogens can also induce ER stress directly or indirectly in host cells (Joyce et al., 2009; Merquiol et al., 2011; Muralidharan and Mandrekar, 2013; Blazquez et al., 2014; Chan, 2014; Liu and Dudley, 2014; Smith, 2014). Components of pathogen can interact with TLRs to influence cellular stress response. Martinon et al. (2010) showed that stimulation with TLR4 or TLR2 ligands activated the UPR sensor IRE1 $\alpha$ and its downstream target, $\mathrm{X}$ box-binding protein (XBP1). The authors indicated that TLR-induced IRE1/XBP1 activation was required for optimal and sustained production of proinflammatory cytokines from macrophages. Notably, XBP1-deficient mice had reduced production of inflammatory mediators and significantly increased bacterial burden when infected with intracellular pathogen Francisella tularensis. This novel finding suggests that TLR and IRE1-XBP1 pathways acted in synergy to maximize innate immune responses to pathogens. Interestingly, Woo et al. (2009, 2012) found that the ATF4/CHOP branch of ER stress signaling pathways was selectively suppressed by TLR 3 or 4 through a TRIF-dependent pathway. In mice pretreated with LPS, a TLR4 ligand, ER stress-induced CHOP expression and apoptosis in macrophages, renal tubule cells, and hepatocytes were suppressed. Accordingly, TLR engagement protected mice from ER stress-induced renal dysfunction and hepatosteatosis. Results from those studies suggest that host innate immune pathways modulate ER-stress response to enhance inflammation, thereby the host defense response, while suppress apoptosis pathways during pathogen infections. In addition to the cross-talk of TLR and UPR pathways, viral infection is frequently associated with ER stress and UPR response because of viral protein synthesis and assembly during viral life cycle. A striking example is hepatitis $\mathrm{C}$ virus $(\mathrm{HCV})$ infection, which is a strong risk factor for chronic liver diseases and hepatocellular carcinoma. The ER stress and inflammation induced by HCV contribute to chronic liver diseases such as hepatic steatosis and cirrhosis though further studies are needed (Joyce et al., 2009; Merquiol et al., 2011; Chan, 2014).

Since there are a number of excellent reviewers on ER stress and UPR pathways (Bertolotti et al., 2000; Eizirik and Cnop, 2010;
McGuckin et al., 2010; Malhi and Kaufman, 2011; Pfaffenbach and Lee, 2011; Cnop et al., 2012; Garg et al., 2012; Hetz, 2012; Logue et al., 2013; Chan, 2014; Smith, 2014; Zhou and Liu, 2014), this review will focus on ER stress-associated inflammation. ER stress can initiate several signaling pathways that induce inflammation, including ROS production, NF-кB pathway, JNK pathway, and autophagy (McGuckin et al., 2010; Garg et al., 2012; Pagliassotti, 2012). Experimental evidence has indicated that all three major UPR sensors are involved in inflammatory response. However, the IRE1 $\alpha$ pathway may play a dominant role in the upregulation of inflammatory cytokines, chemokines, and tissue remodeling molecules. The interaction between IRE1 $\alpha$ and TRAF2 activates NF- $\kappa \mathrm{B}$ and JNK pathways, which are critical for the expression of cytokines, chemokines, and other inflammatory mediators (Urano et al., 2000; Pincus etal., 2010; Zhang et al., 2011; Lerner et al., 2012; Oikawa et al., 2012; Tam et al., 2012; Upton et al., 2012; Qiu et al., 2013). Our following discussion will be centered on hepatic steatosis and inflammatory bowel diseases to illustrate the interplay between ER stress and inflammation (Figure 1).

\section{ER STRESS-INDUCED INFLAMMATION IN HEPATIC STEATOSIS}

As a vital organ for protein synthesis and detoxification, liver is especially susceptible to ER stress. Non-alcoholic fatty liver disease (NAFLD), a spectrum of metabolic disorders ranging from steatosis (NAFL) to steatohepatitis (NASH) to cirrhosis, is the foremost cause of non-alcoholic and non-viral liver-associated illness and death in the US (Kleiner and Brunt, 2012; Larrain and Rinella, 2012; Milic and Stimac, 2012; Pagliassotti, 2012; Tuyama and Chang, 2012; Wierzbicki and Oben, 2012; Ibrahim et al., 2013). Hepatic steatosis or fatty liver can progress to NASH, characterized by progressive liver injury, inflammation, and fibrosis. NASH is also associated with obesity, type 2 diabetes, and liver cancer development (Kleiner and Brunt, 2012; Tuyama and Chang, 2012; Wood, 2012). While ER stress is important for maintaining liver homeostasis, dysregulated ER stress contributes to the pathogenesis of various liver diseases. Accumulating evidence suggests that the interaction between ER stress and inflammation also promote liver steatosis and injury (Malhi and Kaufman, 2011; Cnop et al., 2012; Pagliassotti, 2012; Lake et al., 2013).

\section{ER STRESS AND HEPATIC STEATOSIS}

Although clinical and experimental data implicate the involvement of ER stress in liver diseases, the role and mechanism of ER stress in liver diseases remain not fully understood. A number of studies indicate that ER stress induces liver steatosis through regulating lipid synthesis and inflammation (Malhi and Kaufman, 2011; Li et al., 2012; Pagliassotti, 2012; Wierzbicki and Oben, 2012). This notion is supported by mice carrying genetic mutations of ER stress molecules, or by directly inducing ER stress in vivo via administration of chemical reagents (Birkenfeld et al., 2011; Ji etal., 2011; Zhang et al., 2011; Li et al., 2012; Nagarajan et al., 2012; Petrasek et al., 2012; Chen et al., 2013; Guo et al., 2013; Hamano et al., 2013). For example, Tunicamycin (TM), a widely used ER stress inducer, is a nucleoside antibiotics that blocks N-linked glycosylation, causing accumulation of unfolded or misfolded proteins in the ER lumen. Injection of TM into 


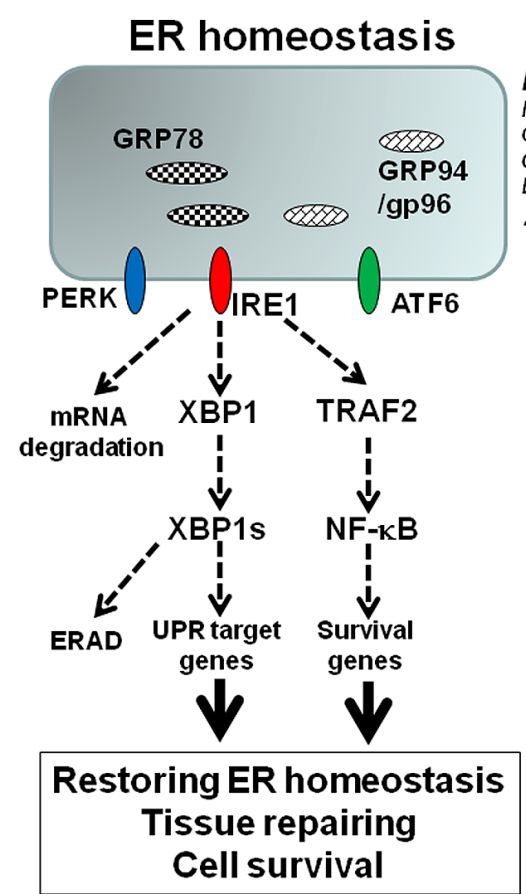

FIGURE 1 |The model of ER stress-associated inflammation.

Accumulation of misfolded proteins, genetic mutations of ER stress molecules, or pharmacological compounds cause ER stress, which triggers the activation of three major UPR sensors: IRE1 $\alpha$, PERK, and ATF6. Activation of IRE1 pathway leads to the unconventional splicing of XBP-1, which control the transcription of a group of UPR genes including GRP78 and GRP94. The interaction of IRE1 and TRAF2 leads to NF-кB activation, which upregulates survival genes. The signaling and transcription programs initiated by IRE1 and

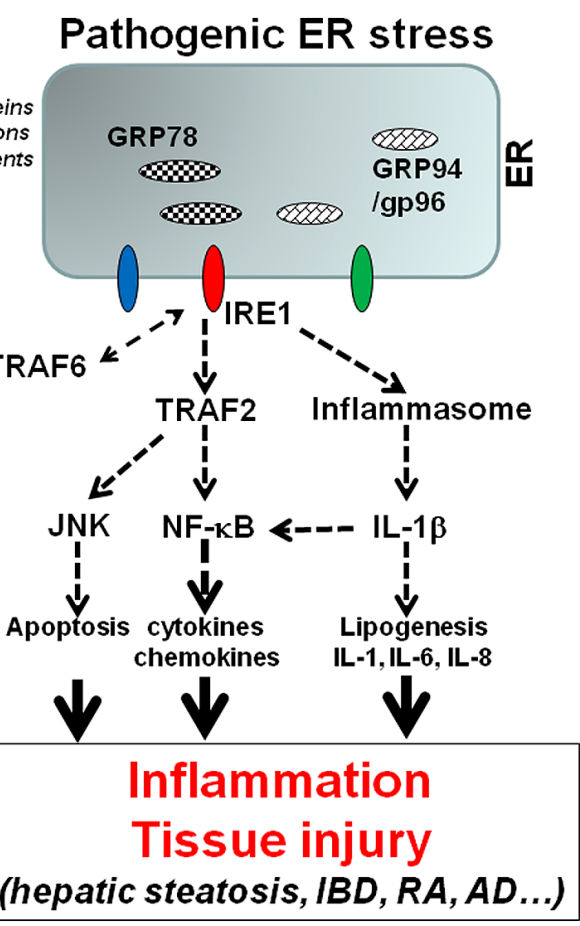

other UPR pathways can restore the ER homeostasis. However, prolonged or unresolved ER stress leads to inflammation. Sustained interaction of IRE1 and TRAF2 leads to NF-kB and JNK activation, which promote inflammatory cytokine production and apoptosis. IRE1 is also involved in ER stress-induced inflammasome activation and $\mathrm{IL}-1 \beta$ production, which in turn induces other inflammatory cytokines such as IL-6 and IL-8. In addition, TRAF6 can mediate IRE1 ubiquitination, which is required for TLR mediated optimal inflammatory cytokine production. mice results in ER stress-mediated liver steatosis and lipogenesis (Zhang et al., 2011; Lee et al., 2012a,b). These findings indicate the potential pathological role of ER stress in the development of hepatic steatosis. On the other hand, obesity and liver steatosis have been shown to induce ER stress. For instance, mice with high fat feeding not only develop hepatic steatosis, insulin resistance, and type 2 diabetes, but also exhibit ER stress markers in liver and other tissues (Yang et al., 2010; Zhou and Liu, 2010; Birkenfeld et al., 2011). Thus ER stress and hepatic steatosis can form a positive feedback loop to further amplify liver inflammation and injury.

Several genetic strategies have been applied to tease out the roles of ER stress and chaperones in liver steatosis. The ER chaperone protein GRP78 is a critical regulator of ER homeostasis and stress responses, because it interacts and sequesters all major UPR sensors (Ye et al., 2010; Pfaffenbach and Lee, 2011). Kammoun et al. (2009) found that overexpression of GRP78 inhibited ER stress-induced sterol regulatory element binding protein (SREBP) expression and steatosis in the livers of obese (ob/ob) mice. Conversely, Ji et al. (2011) showed that GRP78 deletion led to liver fat accumulation and steatosis. Using conditional GRP78 KO mouse model, Ji et al. (2011) found that liver-specific deletion of GRP78 led to ER stress and apoptosis. These conditional KO mice also displayed liver injury and steatosis. Furthermore, the authors showed that liver-specific deletion of GRP78 exacerbated liver injury and/or steatosis induced by alcohol, high-fat diet, drugs, and toxins (Ji et al., 2011). These findings underscore the critical role of ER tress and GRP78 in liver homeostasis and viability in normal or disease conditions.

Results from Zhang et al. (2011) also demonstrate that ER is not only important for protein quality control, but also critical for lipid synthesis and metabolism. ER stress induces hepatic steatosis through upregulation of transcriptional factors essential for lipogenesis, including CCAAT/enhancer-binding protein $\beta$ $(\mathrm{C} / \mathrm{EBP} \beta)$, peroxisome proliferator-activated receptor $\gamma(\operatorname{PPAR} \gamma)$, and SREBP. Zhang et al. (2011) showed that the most conserved UPR sensor IRE1 $\alpha$ protected animals from ER stress-induced hepatic steatosis. To study the role of IRE1 in liver steatosis, the authors generated a hepatocyte-specific IRE1 $\alpha$ deficient mouse line. Deletion of IRE1 $\alpha$ gene resulted in profound hepatosteatosis and hypolipidemia in mice under conditions of ER stress induced by proteasome inhibitor Bortezomib, or partial hepatectomy (Zhang et al., 2011). Results from this study further demonstrated that IRE1 $\alpha$ represses the expression of transcriptional factors in lipid metabolism pathways, including $\mathrm{C} / \mathrm{EBP} \beta, \mathrm{C} / \mathrm{EBP} \delta$, and PPAR $\gamma$ (Zhang et al., 2011). The authors proposed that IRE1 is required for maintaining hepatic lipid homeostasis under ER stress conditions. 


\section{THE INTERACTION OF IRE1 AND TRAF PROTEINS IN NF- $\ltimes B$ ACTIVATION}

IRE $1 \alpha$ plays a critical role in transcription of inflammatory genes due to its interaction with TRAF2, which promotes NF$\kappa \mathrm{B}$ activation and inflammatory response. The TRAF family proteins are intracellular adaptors that have been extensively studied in the signaling pathways of TNFR or IL-1/TLR superfamilies (Chung et al., 2002; Oganesyan et al., 2006; Bishop et al., 2007). All TRAF family proteins (TRAF1-7) have the most conserved TRAF domains in their carboxyl terminal region, which involve in binding to different receptor cytoplasmic tails and the formation of homo- or hetero-dimers between the family members. In addition, all TRAF proteins except TRAF1 have ring fingers, which may function as E3 ubiquitin ligase. Ubiquitination has been shown to play an important role in NF- $\kappa$ B and other signal pathways (Chen, 2005; Pineda etal., 2007; Ha et al., 2009). NF- $\kappa \mathrm{B}$ is a homo or heterodimeric transcription factor that binds to $\kappa \mathrm{B}$ sites in the promoters of a large number of genes involved in cell survival, inflammation, and immune responses (Senftleben and Karin, 2002; Chen, 2005). The activity of NF- $\kappa \mathrm{B}$ is tightly regulated by members of the I $\kappa$ family. In the classical NF- $\kappa$ B pathway, receptor engagement leads to the activation of the IкB kinase (IKK) complex, which includes IKK $\alpha$, IKK $\beta$, and IKK $\gamma$ (NEMO). The activated IKKs

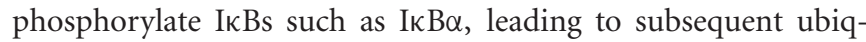

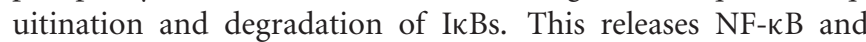
allows it to enter the nucleus and activate transcription of appropriate gene targets (Razani and Cheng, 2010; Dev et al., 2011). NF- $\kappa \mathrm{B}$ dimers are composed of the five Rel family members

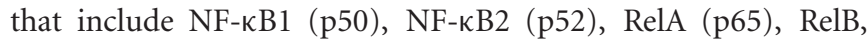
and $c$-Rel. The function of each individual NF- $\kappa \mathrm{B}$ molecule is influenced by binding partners and other upstream molecules. Several early studies suggested that UPR sensor IRE1 $\alpha$ and signaling molecule TRAF2 are required for activation of NF- $\kappa \mathrm{B}$ in response to ER stress-inducing agents, Thapsigargin and TM. Kaneko et al. (2003) showed that ER stress-induced NF- $\kappa$ B activation was inhibited by a dominant-negative form of IRE1 or TRAF2. Hu etal. (2006) also showed that ER stress-induced NF- $\kappa \mathrm{B}$ activation was impaired in IRE $1 \alpha$ knockdown cells and IRE1 KO MEFs. The authors further demonstrated that TRAF2 provided a critical link between UPR/IRE1 signaling and downstream IKK/NF- $\kappa \mathrm{B}$ activation. Biochemical experiments showed that in response to ER stress, IRE $1 \alpha$ formed a signaling complex with IKKs though the adapter protein TRAF2 (Hu et al., 2006). Although those studies suggested that the interaction of IRE1, TRAF2, and IKK plays an important role in ER stress-induced NF- $\kappa \mathrm{B}$ activation, how IRE $1 \alpha$ activates the IKK complex is poorly characterized. Furthermore, the function of IRE1 and TRAF2 in ER stress-induced NF- $\kappa \mathrm{B}$ activation in vivo needs to be further explored.

\section{ER STRESS-INDUCED INFLAMMASOME ACTIVATION}

IL-1 $\beta$ and other IL-1 family members are major mediators in inflammation. Production of mature IL- $1 \beta$ is regulated by at least two signals: TLR-mediated transcriptional upregulation of pro-IL-1 $\beta$ gene, and inflammasomes-mediated IL-1 $\beta$ maturation (Cassel etal., 2009; Leemans et al., 2011; Rathinam et al., 2012; Wen etal., 2012). An inflammasome is a multiprotein signaling complex, composed of NOD-like protein (NLR) such as NLRP3, the adaptor apoptosis-associated speck-like protein containing a caspase recruitment domain (ASC), and caspase-1. Activation of an inflammasome triggers autoproteolytic cleavage of pro-caspase- 1 into its active form, which subsequently processes pro-IL-1 $\beta$ into its mature form (Cassel et al., 2009; Horng and Hotamisligil, 2011; Menu and Vince, 2011; Vandanmagsar et al., 2011). Although very diverse and unrelated stimuli are found to trigger the activation of inflammasomes, the molecular mechanisms responsible for inflammasome activation remain elusive.

Recent progress suggests that inflammasomes play a critical role in a number of autoimmune and metabolic diseases. However, inflammasome activities have been shown to promote or protect liver steatosis (Imaeda et al., 2009; Petrasek et al., 2012; Szabo and Csak, 2012; Wood, 2012). Because of the important role of both ER stress and inflammasome in inflammation, we hypothesize that ER stress and inflammasome activity are interconnected during liver injury and steatosis. While several recent studies demonstrated that ER stress induces pro-IL-1 $\beta$ mRNA expression or NLRP3 inflammasome activation, whether or not UPR pathways are involved in inflammasome activation remains controversial (Lerner et al., 2012; Menu et al., 2012; Oslowski et al., 2012; Shenderov et al., 2014). For instance, an early study from Tschopp's group suggested that ER stress triggered NLRP3 inflammasome activation in THP-1 cells, a macrophage/monocyte cell line, in a mechanism that is independent of the classical ER stress signaling pathways (Lerner et al., 2012; Menu et al., 2012; Oslowski et al., 2012), whereas other groups suggested that IRE1 $\alpha$ under irremediable ER stress induced pro-IL-1 $\beta$ mRNA expression via thioredoxin-interacting protein, which was also associated with programmed cell death of pancreatic $\beta$ cells. Further studies in our and other laboratories are ongoing to elucidate the molecule mechanisms by which ER stress induces NLRP3 inflammasome activation and IL-1 $\beta$ production.

\section{URP SIGNALING PATHWAYS INVOLVED IN LIVER INFLAMMATION}

In addition to NF- $\mathrm{B}$ pathway, IRE1/TRAF2 can activate other transcription factors such as AP-1, which is also important for the expression of inflammatory cytokines. PERK and ATF6 pathways have also been reported to activate NF-кB (Yamazaki et al., 2009; Nakajima et al., 2011; Tam et al., 2012); however, the mechanisms of PERK or ATF6-medaited NF- $\kappa$ B activation remain unknown. In addition, activation of UPR leads to the generation of ROS, which can induce inflammatory response. All these UPR pathways potentially contribute to liver steatosis and inflammation. However, the relative contribution of each pathway is unclear. Furthermore, NFALD progression is associated with increased apoptosis of hepatocytes. It has been suggested that severe or chronic ER stress can cause cell death via induction of the CHOP pathway (Nishitoh, 2012; Han et al., 2013). The UPR pathways PERK and ATF6 branches are responsible for the activation of CHOP. IRE1 pathway can also induce cell death through either IRE1/TRAF2-mediated JNK activation or direct interaction with Bac and Bak proapoptotic proteins (Kato et al., 2012). It is possible that cell death under severe ER stress conditions leads to sterile inflammation and tissue damage in liver. 


\section{INFLAMMATORY BOWEL DISEASES (IBD)}

IBD, including Crohn's disease (CD) and ulcerative colitis (UC), is a complex intestinal tract disease involving various immune cells, epithelial cells, and intestinal microflora (Strober et al., 2007; Buonocore et al., 2010; Fritz et al., 2011; Papatriantafyllou, 2011; Jostins et al., 2012). Genetic studies have identified many genes, most related with immune response such as IL-10, TLR, NOD2, and IL-23, autophagy and ER stress, that are associated with the development of intestinal inflammation (Hugot et al., 2001; Van Limbergen et al., 2007; Okazaki et al., 2008; Abraham and Cho, 2009; Sarra et al., 2010; Begue et al., 2011; Fritz et al., 2011). Intestinal epithelial cells (IECs) are constantly exposed to gut microflora. One of major functions of intestinal Paneth cells and goblet cells is secretion of various factors essential for the intestinal homeostasis and host defense. Furthermore, macrophages and DCs actively produce inflammatory cytokines in response to translocated bacteria or bacterial components. Therefore, the intestinal system is highly susceptible to ER stress. The interaction of innate and microflora contributes to intestinal inflammation in both acute and chronic colitis. Several excellent studies using genetic mutant mice have highlight the critical role of ER stress in the pathogenesis of colitis.

\section{GRP94 IN GUT HOMEOSTASIS AND INFLAMMATION}

Recent studies from others and our group have demonstrated that ER HSP protein GRP94 is a critical chaperone for multiple TLRs and integrins (Yang et al., 2007). To study the role of ER chaperones in the intestinal homeostasis and inflammation, Liu et al. (2013) generated conditional GRP94 KO mice and intestinal tissue-specific GRP 94 KO mice. In the tamoxifen-inducible GRP94 KO mice, deletion of GRP94 led to rapid weight loss, diarrhea, and ultimately death 12-14 days post-tamoxifen injection. While not affecting embryo development, gut-specific deletion of GRP94 was associated with postnatal death of mutant mice. Pathological analysis demonstrated that GRP94 loss compromised the intestinal barrier function with significant intestinal dilatation, edema and hemorrhage, and thickening of the intestinal wall. The authors further demonstrated that GRP94 maintained gut homeostasis through direct regulation of canonical Wntsignaling pathway. The results showed that GRP94 interacted with mesoderm development (MesD), an ER chaperone essential for the Wnt coreceptor low-density lipoprotein receptor-related protein 6 (LRP6; Liu et al., 2013). The Wnt/ $\beta$-catenin signaling pathway has been shown previously to be critical for intestinal homeostasis (Krausova and Korinek, 2014). Mechanistically, GRP94 deletion impaired export of LRP6 from ER to the cell surface, leading to profound loss of gut intrinsic Wnt signaling and intestinal homeostasis. This finding underscores the importance of GRP94 in chaperoning the canonical LRP6/Wnt signal pathway.

\section{THE IRE1-XBP1 PATHWAY IN INTESTINAL HOMEOSTASIS}

Several studies implicated UPR pathways in intestinal inflammation and colitis. Bertolotti et al. (2001) showed that IRE1 $\beta$ deficient mice exhibited increased sensitivity to acute colitis induced by dextran sodium sulfate (DSS). The authors found that expression of IRE1 $\beta$ was restricted to the epithelium of the gastrointestinal tract. DSS treatment led to elevated levels of ER stress markers and increased severity of colitis in IRE1 $\beta$ KO mice, compared with WT mice (Bertolotti et al., 2001). It is unclear whether increased ER stress in IECs was caused by espousing of gut epithelial cells to microflora or by intestinal inflammation after DSS treatment. Nevertheless, these results suggest that deletion of UPR sensor IRE1 $\beta$ disrupted intestinal homeostasis in response to environmental challenge. IRE1 has two forms, IRE1 $\alpha$ and IRE1 $\beta$, encoded by two distinct genes. It is noteworthy that untreated IRE1 $\beta$ deficient mice showed no sign of intestinal inflammation histologically (Bertolotti et al., 2001). One of reasons might be the redundant role of IRE1 $\alpha$ and IRE1 $\beta$. However, whether specific deletion of IRE1 $\alpha$ in the IECs enhances the susceptibility to DSS-induced colitis has not been reported.

The involvement of IRE1 pathway in colitis is also supported by $\mathrm{XBP} 1$ conditional KO mice (Kaser et al., 2008). As a ribonuclease, an important substrate of IRE1 is the mRNA for transcriptional factor XBP1. Activated IRE1 splices the XBP1 mRNA by the excision of a 26bp fragment via an unconventional splicing mechanism, generating spliced XBP1 (XBP1s; Adolph et al., 2012; Upton et al., 2012). XBP1s controls the transcription of a set of UPR target genes, including chaperones, protein disulfide isomerases (PDIs), and components of ERAD, essential for the maintenance of ER function. Furthermore, XBP1 plays a critical role in the development of highly secretory cells such as plasma cells and pancreatic cells (Glimcher, 2010; Sha et al., 2011). Dr. Blumberg's group reported that mice with tissue-specific deletion of XBP1 in IECs developed spontaneous enteritis and displayed increased susceptibility to DSS-induced colitis (Kaser et al., 2008). Kaser et al. (2008) showed that mice deficient in XBP-1 in intestinal tissues displayed spontaneous intestinal inflammation characterized by immune cell infiltration, loss of crypts, and ulceration. Strikingly, deletion of XBP1 in IECs also resulted in the reduced number of Paneth and goblet cells (Kaser et al., 2008; Adolph et al., 2013). A major function of Paneth cells is to secret antimicrobial peptides. Goblet cells are IECs that produce protective mucus in the microbiota-intestine interface. The diminished function or number of both cell types rendered these XBP1 deficient mice more susceptible to DSS-induced colitis. The authors also found that XBP-1 deficient intestinal tissues had increased expression of ER stress mediators such as GRP78, ATF4, and CHOP (Kaser et al., 2008). Enhanced ER stress may lead to more inflammation in response to gut microflora. In addition, upregulation of CHOP may contribute to apoptosis of Paneth cells in XBP-1 deficient mice. Thus, dysregulated ER stress in IEC compartment induces intestinal inflammation and colitis. Kaser et al. (2008) also found the association of XBP1 variants with both $\mathrm{CD}$ and $\mathrm{UC}$, indicating XBP1 as a genetic risk factor for human IBD.

\section{INFLAMMASOME ACTIVATION IN THE DEVELOPMENT OF COLITIS}

The role of inflammasomes as well as their interaction with microbiota in intestinal inflammation is an active area of research. Up to now, a number of publications have painted a more complex picture of inflammasomes in colitis and colitis-associated colon cancer (Sands, 2007; Bauer et al., 2010, 2012; Zaki et al., 2010; 
Henao-Mejia et al., 2012b). Moreover, the interaction between ER stress pathways and inflammasomes is still yet to be established. Several studies showed that mice deficient for inflammasome components including NLRP3, ASC, and caspase-1 were highly susceptible to acute colitis induced by DSS, indicating the protective role of inflammasome in acute colitis (Allen et al., 2010; Dupaul-Chicoine et al., 2010; Hirota et al., 2011). However, Bauer et al. (2010) showed that that defective in NLRP3 inflammasome protected mice from DSS-induced acute colitis, indicating that inflammasomes contribute to the development of colitis. Our recent study showed that inflammasome activation promoted the intestinal inflammation in IL-10 KO mice, which develops chronic colitis resembling human IBD. We also found that inhibition of inflammasome activities with IL-1 receptor antagonist or caspase-1 inhibitors suppressed intestinal inflammation (Zhang et al., 2014). Our data further suggest that inflammasome-derived IL-1 $\beta$ promoted Th17 phenotype in intestinal tissues. Those results indicate that without inhibitory effects of IL-10, the interaction between inflammasomes and microbiota leads to intestinal inflammation and the development of colitis.

\section{ER STRESS AND INFLAMMATION IN COLITIS-ASSOCIATED COLON CANCER}

Inflammation contributes to tumor initiation and progression, especially for colitis-associated colon cancer. Because of unregulated growth and hypoxia environments, ER stress is associated with tumor development. Depending on type or stage of tumor development, ER stress can enhance or suppress tumor development (Ghiringhelli etal., 2009; Allen etal., 2010; Hu et al., 2011; Bruchard et al., 2013). Moreover, Mahadevan et al. (2011) found that ER stress from stressed tumor cells could be transmitted to other neighborhood cells via un-identified heat-stable molecules. Conditioned media derived from cancer cells with ER stress could induce ER stress markers such as XBP-1, GRP78, and CHOP in macrophages, leading to production of inflammatory molecules (Mahadevan et al., 2011). It is possible that this kind of transmissible ER stress could amplify inflammation in tumor microenvironments.

Because most studies on ER stress and tumor development are focused on tumor-intrinsic stress pathways, research on ER stress and inflammation in tumor microenvironments is limited so far. Using macrophage-specific KO mice, Morales et al. (2014) showed that mice with macrophage-specific deletion of GRP94/gp96 exhibited decreased colitis and inflammationassociated colon cancer induced by DSS/AOM, with reduced expression of inflammatory cytokines such as IL-6, IL-17, and IL-23. These results demonstrate the macrophage-intrinsic role of chaperone GRP96 in promoting colitis and inflammationassociated colon tumorigenesis.

Similar to its controversial role in colitis, inflammasomes also have a complex role in tumor development. A study by Allen et al. (2010) showed that NLRP3-deficient mice were more sensitive

Table 1 | A list of diseases linked to dysregulated ER stress.

\begin{tabular}{|c|c|}
\hline Diseases & Reference \\
\hline \multicolumn{2}{|l|}{ Metabolic diseases } \\
\hline Hepatic steatosis & Malhi and Kaufman (2011), Zhang etal. (2011) \\
\hline Type 2 diabetes mellitus & Papa (2012), Biden et al. (2014) \\
\hline Obesity & Kawasaki et al. (2012), Tripathi and Pandey (2012) \\
\hline Atherosclerosis & McAlpine and Werstuck (2013), Zhou and Tabas (2013) \\
\hline \multicolumn{2}{|l|}{ Autoimmune diseases } \\
\hline Arthritis & Yoo et al. (2012), Qiu et al. (2013), Savic et al. (2014) \\
\hline Inflammatory diseases & Kaser etal. (2008), Liu etal. (2013) \\
\hline Chronic pulmonary diseases & Blohmke et al. (2012), Blumental-Perry (2012) \\
\hline \multicolumn{2}{|l|}{ Neurodegenerative diseases } \\
\hline Alzheimer's disease & Cornejo and Hetz (2013), Li etal. (2014) \\
\hline Parkinson's disease & Bellucci et al. (2011), Vidal etal. (2012), Mercado etal. (2013) \\
\hline Multiple sclerosis & Cunnea et al. (2011), McMahon et al. (2012) \\
\hline \multicolumn{2}{|l|}{ Pathogen infections } \\
\hline Viral infection & Chan (2014), Tesh (2012), Blazquez etal. (2014) \\
\hline Bacterial infection & Martinon et al. (2010), Lee etal. (2013) \\
\hline \multicolumn{2}{|l|}{ Tumor } \\
\hline Breast cancer & Martin-Perez et al. (2014), Zheng etal. (2014) \\
\hline Colon cancer & Hardy etal. (2012), Morales et al. (2014) \\
\hline Leukemia and lymphomas & Mahoney etal. (2013), Kharabi Masouleh etal. (2014) \\
\hline Hepatocellular carcinoma & Shuda etal. (2003), Tang etal. (2012), Chen etal. (2013) \\
\hline Pancreatic cancer & Kubisch and Logsdon (2008), Romero-Ramirez etal. (2009) \\
\hline
\end{tabular}


to colorectal tumorigenesis. The authors found that mice deficient for NLRP3 inflammasome components including NLRP3, ASC or caspase-1 had severe colitis and increased tumorigenesis in AOM/DSS colon cancer model. But NLRC4 KO mice displayed similar incidence of colitis-associated colon cancer as WT mice. The authors further demonstrated that NLRP3-inflammasome activation in bone marrow-derived cells was critical for the tumor suppression. In contrast, $\mathrm{Hu}$ et al. (2011) found that caspase$1 \mathrm{KO}$ and NLRC4 KO mice, but not NLRP3 KO mice, had increased tumorigenesis in the AOM/DSS colon cancer model. Furthermore, NLR6 and NLR12 also have been shown to suppress tumor development in AOM/DSS colon cancer model (Chen and Nunez, 2011; Chen et al., 2011). A possible explanation is that inflammasome-processed IL-1 and IL-18 signaling in IECs provides protection against apoptosis of gut epithelial cells. Those studies imply that the inflammasomes may promote or suppress colon cancer development depending on experimental conditions, possibly gut microflora.

\section{ER STRESS AND INFLAMMATION IN OTHER DISEASES}

ER stress-induced inflammation is also associated with other metabolic (Kawasaki et al., 2012; Papa, 2012; Tripathi and Pandey, 2012; McAlpine and Werstuck, 2013; Zhou and Tabas, 2013; Biden et al., 2014), inflammatory (Blohmke et al., 2012; Blumental-Perry, 2012; Yoo et al., 2012; Qiu et al., 2013; Savic et al., 2014), neurodegenerative diseases (Bellucci et al., 2011; Cunnea et al., 2011; McMahon et al., 2012; Vidal et al., 2012; Cornejo and Hetz, 2013; Mercado et al., 2013; Li et al., 2014), pathogen infections (Martinon et al., 2010; Merquiol et al., 2011; Tesh, 2012; Lee et al., 2013; Blazquez et al., 2014; Chan, 2014), and cancer (Shuda et al., 2003; Kubisch and Logsdon, 2008; Romero-Ramirez et al., 2009; Hardy et al., 2012; Tang et al., 2012; Chen et al., 2013; Mahoney et al., 2013; Kharabi Masouleh et al., 2014; Martin-Perez et al., 2014; Shimodaira et al., 2014; Zheng et al., 2014). While this review focuses on liver steatosis and inflammatory bowl diseases, Table 1 listed various diseases where pathogenesis has directly or indirectly been linked to ER stress.

\section{CONCLUSION AND PERSPECTIVES}

ER stress functions as an adaptive response to maintain cell homeostasis and survival when normal protein or lipid synthesis and metabolism are perturbed. Emerging evidence indicates that ER stress is also closely associated with inflammation, in addition to its classic role in protein quality control. We propose that the IRE1/TRAF2 axis represents a major pathway to link ER stress with key transcription factors such as NF- $\kappa$ B that controls the expression of inflammatory cytokine genes. We also speculate that the interaction between UPR pathways and inflammasomes provides another link between ER stress and inflammation. While the activation of UPR pathways can lead to resolving the ER stress and achieving new protein homeostasis, prolonged and severe ER stress can result in cell death and tissue damage, contributing to the pathogenesis of various diseases. In both scenarios, inflammation can be induced in stressed cells and surrounding cells. In a broad term, inflammatory diseases such as IBD and hepatic steatosis are the results of interaction amongst ER stress, inflammatory cytokines, metabolism, and gut microflora (Machado and Cortez-Pinto, 2012). Similarly, ER stress and inflammation can promote or inhibit the development of colitis-associated cancer depending on genetic background, environments, and intestinal microflora. A better understanding of ER stress and inflammation may lead to identification of potential therapeutic targets for the treatment of inflammatory and metabolic diseases as well as cancer.

\section{ACKNOWLEDGMENTS}

This work was supported by NIH grants AI070603, AI077283, and HL100556 (to Zihai Li); NIAID K22 AI87707, and Hollings Cancer Center the American Cancer Society Institutional Research Grant 016623-016 (Beichu Guo).

\section{REFERENCES}

Abraham, C., and Cho, J. H. (2009). IL-23 and autoimmunity: new insights into the pathogenesis of inflammatory bowel disease. Annu. Rev. Med. 60, 97-110. doi: 10.1146/annurev.med.60.051407.123757

Adolph, T. E., Niederreiter, L., Blumberg, R. S., and Kaser, A. (2012). Endoplasmic reticulum stress and inflammation. Dig. Dis. 30, 341-346. doi: $10.1159 / 000338121$

Adolph, T. E., Tomczak, M. F., Niederreiter, L., Ko, H. J., Bock, J., Martinez-Naves, E., et al. (2013). Paneth cells as a site of origin for intestinal inflammation. Nature 503, 272-276. doi: 10.1038/nature12599

Allen, I. C., Tekippe, E. M., Woodford, R. M., Uronis, J. M., Holl, E. K., Rogers, A. B., et al. (2010). The NLRP3 inflammasome functions as a negative regulator of tumorigenesis during colitis-associated cancer. J. Exp. Med. 207, 1045-1056. doi: 10.1084/jem.20100050

Bauer, C., Duewell, P., Lehr, H. A., Endres, S., and Schnurr, M. (2012). Protective and aggravating effects of Nlrp3 inflammasome activation in IBD models: influence of genetic and environmental factors. Dig. Dis. 30(Suppl. 1), 82-90. doi: 10.1159/000341681

Bauer, C., Duewell, P., Mayer, C., Lehr, H. A., Fitzgerald, K. A., Dauer, M., et al. (2010). Colitis induced in mice with dextran sulfate sodium (DSS) is mediated by the NLRP3 inflammasome. Gut 59, 1192-1199. doi: 10.1136/gut.2009. 197822

Begue, B., Verdier, J., Rieux-Laucat, F., Goulet, O., Morali, A., Canioni, D., et al. (2011). Defective IL10 signaling defining a subgroup of patients with inflammatory bowel disease. Am. J. Gastroenterol. 106, 1544-1555. doi: 10.1038/ajg.2011.112

Bellucci, A., Navarria, L., Zaltieri, M., Falarti, E., Bodei, S., Sigala, S., et al. (2011). Induction of the unfolded protein response by alpha-synuclein in experimental models of Parkinson's disease. J. Neurochem. 116, 588-605. doi: 10.1111/j.14714159.2010.07143.x

Bertolotti, A., Wang, X., Novoa, I., Jungreis, R., Schlessinger, K., Cho, J. H., etal. (2001). Increased sensitivity to dextran sodium sulfate colitis in IRE1beta-deficient mice. J. Clin. Invest. 107, 585-593. doi: 10.1172/ JCI1 1476

Bertolotti, A., Zhang, Y., Hendershot, L. M., Harding, H. P., and Ron, D. (2000). Dynamic interaction of $\mathrm{BiP}$ and ER stress transducers in the unfolded-protein response. Nat. Cell Biol. 2, 326-332. doi: 10.1038/35014014

Biden, T. J., Boslem, E., Chu, K. Y., and Sue, N. (2014). Lipotoxic endoplasmic reticulum stress, beta cell failure, and type 2 diabetes mellitus. Trends Endocrinol. Metab. doi: 10.1016/j.tem.2014.02.003 [Epub ahead of print].

Birkenfeld, A. L., Lee, H. Y., Majumdar, S., Jurczak, M. J., Camporez, J. P., Jornayvaz, F. R., et al. (2011). Influence of the hepatic eukaryotic initiation factor 2alpha (eIF2alpha) endoplasmic reticulum (ER) stress response pathway on insulinmediated ER stress and hepatic and peripheral glucose metabolism. J. Biol. Chem. 286, 36163-36170. doi: 10.1074/jbc.M111.228817

Bishop, G. A., Moore, C. R., Xie, P., Stunz, L. L., and Kraus, Z. J. (2007). TRAF proteins in CD40 signaling. Adv. Exp. Med. Biol. 597, 131-151. doi: 10.1007/9780-387-70630-6_11

Blazquez, A. B., Escribano-Romero, E., Merino-Ramos, T., Saiz, J. C., and MartinAcebes, M. A. (2014). Stress responses in flavivirus-infected cells: activation of unfolded protein response and autophagy. Front. Microbiol. 5:266. doi: 10.3389/fmicb.2014.00266 
Blohmke, C. J., Mayer, M. L., Tang, A. C., Hirschfeld, A. F., Fjell, C. D., Sze, M. A., et al. (2012). Atypical activation of the unfolded protein response in cystic fibrosis airway cells contributes to p38 MAPK-mediated innate immune responses. J. Immunol. 189, 5467-5475. doi: 10.4049/jimmunol. 1103661

Blumental-Perry, A. (2012). Unfolded protein response in chronic obstructive pulmonary disease: smoking, aging and disease: a SAD trifecta. Curr. Mol. Med. 12, 883-898. doi: 10.2174/156652412801318764

Bruchard, M., Mignot, G., Derangere, V., Chalmin, F., Chevriaux, A., Vegran, F., et al. (2013). Chemotherapy-triggered cathepsin B release in myeloid-derived suppressor cells activates the Nlrp3 inflammasome and promotes tumor growth. Nat. Med. 19, 57-64. doi: 10.1038/nm.2999

Buonocore, S., Ahern, P. P., Uhlig, H. H., Ivanov, I. I., Littman, D. R. Maloy, K. J., et al. (2010). Innate lymphoid cells drive interleukin-23-dependent innate intestinal pathology. Nature 464, 1371-1375. doi: 10.1038/nature 08949

Cassel, S. L., Joly, S., and Sutterwala, F. S. (2009). The NLRP3 inflammasome: a sensor of immune danger signals. Semin. Immunol. 21, 194-198. doi: 10.1016/j.smim.2009.05.002

Chan, S. W. (2014). Unfolded protein response in hepatitis C virus infection. Front. Microbiol. 5:233. doi: 10.3389/fmicb.2014.00233

Chen, G. Y., Liu, M., Wang, F., Bertin, J., and Nunez, G. (2011). A functional role for Nlrp6 in intestinal inflammation and tumorigenesis. J. Immunol. 186, 7187-7194. doi: 10.4049/jimmunol.1100412

Chen, G. Y., and Nunez, G. (2011). Inflammasomes in intestinal inflammation and cancer. Gastroenterology 141, 1986-1999. doi: 10.1053/j.gastro.2011.10.002

Chen, W. T., Zhu, G., Pfaffenbach, K., Kanel, G., Stiles, B., and Lee, A. S. (2013) GRP78 as a regulator of liver steatosis and cancer progression mediated by loss of the tumor suppressor PTEN. Oncogene doi: 10.1038/onc.2013.437 [Epub ahead of print].

Chen, Z. J. (2005). Ubiquitin signalling in the NF-kappaB pathway. Nat. Cell Biol. 7 , 758-765. doi: 10.1038/ncb0805-758

Chung, J. Y., Park, Y. C., Ye, H., and Wu, H. (2002). All TRAFs are not created equal: common and distinct molecular mechanisms of TRAF-mediated signal transduction. J. Cell Sci. 115, 679-688.

Cnop, M., Foufelle, F., and Velloso, L. A. (2012). Endoplasmic reticulum stress, obesity and diabetes. Trends Mol. Med. 18, 59-68. doi: 10.1016/j.molmed.2011.07.010

Cornejo, V. H., and Hetz, C. (2013). The unfolded protein response in Alzheimer's disease. Semin. Immunopathol. 35, 277-292. doi: 10.1007/s00281-013-0373-379

Cunnea, P., Mhaille, A. N., Mcquaid, S., Farrell, M., Mcmahon, J., and Fitzgerald, U. (2011). Expression profiles of endoplasmic reticulum stress-related molecules in demyelinating lesions and multiple sclerosis. Mult. Scler. 17, 808-818. doi: $10.1177 / 1352458511399114$

Davis, B. K., Wen, H., and Ting, J. P. (2011). The inflammasome NLRs in immunity, inflammation, and associated diseases. Annu. Rev. Immunol. 29, 707-735. doi: 10.1146/annurev-immunol-031210-101405

Dev, A., Iyer, S., Razani, B., and Cheng, G. (2011). NF-kappaB and innate immunity. Curr. Top. Microbiol. Immunol. 349, 115-143. doi: 10.1007/82_2010_102

Dupaul-Chicoine, J., Yeretssian, G., Doiron, K., Bergstrom, K. S., Mcintire, C. R., Leblanc, P. M., et al. (2010). Control of intestinal homeostasis, colitis, and colitisassociated colorectal cancer by the inflammatory caspases. Immunity 32, 367-378. doi: 10.1016/j.immuni.2010.02.012

Eizirik, D. L., and Cnop, M. (2010). ER stress in pancreatic beta cells: the thin red line between adaptation and failure. Sci. Signal. 3:pe7. doi: 10.1126/scisignal.3110pe7

Eri, R. D., Adams, R. J., Tran, T. V., Tong, H., Das, I., Roche, D. K., et al. (2011). An intestinal epithelial defect conferring ER stress results in inflammation involving both innate and adaptive immunity. Mucosal. Immunol. 4, 354-364. doi: 10.1038/mi.2010.74

Fritz, T., Niederreiter, L., Adolph, T., Blumberg, R. S., and Kaser, A. (2011). Crohn's disease: NOD2, autophagy and ER stress converge. Gut 60, 1580-1588. doi: 10.1136/gut.2009.206466

Garg, A. D., Kaczmarek, A., Krysko, O., Vandenabeele, P., Krysko, D. V., and Agostinis, P. (2012). ER stress-induced inflammation: does it aid or impede disease progression? Trends Mol. Med. 18, 589-598. doi: 10.1016/j.molmed.2012.06.010

Ghiringhelli, F., Apetoh, L., Tesniere, A., Aymeric, L., Ma, Y., Ortiz, C., et al. (2009). Activation of the NLRP3 inflammasome in dendritic cells induces IL1beta-dependent adaptive immunity against tumors. Nat. Med. 15, 1170-1178. doi: $10.1038 / \mathrm{nm} .2028$
Glimcher, L. H. (2010). XBP1: the last two decades. Ann. Rheum. Dis. 69(Suppl. 1), i67-i71. doi: 10.1136/ard.2009.119388

Guo, C. A., Kogan, S., Amano, S. U., Wang, M., Dagdeviren, S., Friedline, R. H., et al. (2013). CD40 deficiency in mice exacerbates obesity-induced adipose tissue inflammation, hepatic steatosis and insulin resistance. Am. J. Physiol. Endocrinol. Metab. 304, E951-E963. doi: 10.1152/ajpendo.00514.2012

Ha, H., Han, D., and Choi, Y. (2009). TRAF-mediated TNFR-family signaling. Curr. Protoc. Immunol. Chap. 11, Unit 11.19D. doi: 10.1002/0471142735.im1109ds87

Hamano, M., Ezaki, H., Kiso, S., Furuta, K., Egawa, M., Kizu, T., et al. (2013). Lipid overloading during liver regeneration causes delayed hepatocyte DNA replication by increasing ER stress in mice with simple hepatic steatosis. J. Gastroenterol. 49, 305-316. doi: 10.1007/s00535-013-0780-787

Han, J., Back, S. H., Hur, J., Lin, Y. H., Gildersleeve, R., Shan, J., et al. (2013). ER-stress-induced transcriptional regulation increases protein synthesis leading to cell death. Nat. Cell Biol. 15, 481-490. doi: 10.1038/ncb2738

Hardy, B., Raiter, A., Yakimov, M., Vilkin, A., and Niv, Y. (2012). Colon cancer cells expressing cell surface GRP78 as a marker for reduced tumorigenicity. Cell Oncol. (Dordr.) 35, 345-354. doi: 10.1007/s13402-012-0094-94

Henao-Mejia, J., Elinav, E., Jin, C., Hao, L., Mehal, W. Z., Strowig, T., et al. (2012a). Inflammasome-mediated dysbiosis regulates progression of NAFLD and obesity. Nature 482, 179-185. doi: 10.1038/nature10809

Henao-Mejia, J., Elinav, E., Strowig, T., and Flavell, R. A. (2012b). Inflammasomes: far beyond inflammation. Nat. Immunol. 13, 321-324. doi: 10.1038/ni.2257

Hetz, C. (2012). The unfolded protein response: controlling cell fate decisions under ER stress and beyond. Nat. Rev. Mol. Cell Biol. 13, 89-102. doi: 10.1038/nrm3270

Hirota, S. A., Ng, J., Lueng, A., Khajah, M., Parhar, K., Li, Y., et al. (2011). NLRP3 inflammasome plays a key role in the regulation of intestinal homeostasis. Inflamm. Bowel Dis. 17, 1359-1372. doi: 10.1002/ibd.21478

Horng, T., and Hotamisligil, G. S. (2011). Linking the inflammasome to obesityrelated disease. Nat. Med. 17, 164-165. doi: 10.1038/nm0211-164

$\mathrm{Hu}$, B., Elinav, E., and Flavell, R. A. (2011). Inflammasome-mediated suppression of inflammation-induced colorectal cancer progression is mediated by direct regulation of epithelial cell proliferation. Cell Cycle 10, 1936-1939. doi: $10.4161 /$ cc. 10.12.16008

Hu, P., Han, Z., Couvillon, A. D., Kaufman, R. J., and Exton, J. H. (2006). Autocrine tumor necrosis factor alpha links endoplasmic reticulum stress to the membrane death receptor pathway through IRElalpha-mediated NF-kappaB activation and down-regulation of TRAF2 expression. Mol. Cell. Biol. 26, 3071-3084. doi: 10.1128/MCB.26.8.3071-3084.2006

Hugot, J. P., Chamaillard, M., Zouali, H., Lesage, S., Cezard, J. P., Belaiche, J., et al. (2001). Association of NOD2 leucine-rich repeat variants with susceptibility to Crohn's disease. Nature 411, 599-603. doi: 10.1038/35079107 35079107

Ibrahim, M. A., Kelleni, M., and Geddawy, A. (2013). Nonalcoholic fatty liver disease: current and potential therapies. Life Sci. 92, 114-118. doi: 10.1016/j.lfs.2012.11.004

Imaeda, A. B., Watanabe, A., Sohail, M. A., Mahmood, S., Mohamadnejad, M., Sutterwala, F. S., et al. (2009). Acetaminophen-induced hepatotoxicity in mice is dependent on Tlr9 and the Nalp3 inflammasome. J. Clin. Invest. 119, 305-314. doi: $10.1172 /$ JCI35958

Ji, C., Kaplowitz, N., Lau, M. Y., Kao, E., Petrovic, L. M., and Lee, A. S. (2011). Liver-specific loss of glucose-regulated protein 78 perturbs the unfolded protein response and exacerbates a spectrum of liver diseases in mice. Hepatology 54, 229-239. doi: 10.1002/hep.24368

Jostins, L., Ripke, S., Weersma, R. K., Duerr, R. H., Mcgovern, D. P., Hui, K. Y., et al. (2012). Host-microbe interactions have shaped the genetic architecture of inflammatory bowel disease. Nature 491, 119-124. doi: 10.1038/nature11582

Joyce, M. A., Walters, K. A., Lamb, S. E., Yeh, M. M., Zhu, L. F., Kneteman, N., et al. (2009). HCV induces oxidative and ER stress, and sensitizes infected cells to apoptosis in SCID/Alb-uPA mice. PLoS Pathog. 5:e1000291. doi: 10.1371/journal.ppat.1000291

Kammoun, H. L., Chabanon, H., Hainault, I., Luquet, S., Magnan, C., Koike, T., et al. (2009). GRP78 expression inhibits insulin and ER stress-induced SREBP-1c activation and reduces hepatic steatosis in mice. J. Clin. Invest. 119, 1201-1215. doi: 10.1172/JCI37007

Kaneko, M., Niinuma, Y., and Nomura, Y. (2003). Activation signal of nuclear factorkappa B in response to endoplasmic reticulum stress is transduced via IRE1 and tumor necrosis factor receptor-associated factor 2. Biol. Pharm. Bull. 26, 931-935. doi: $10.1248 / \mathrm{bpb} .26 .931$ 
Kaser, A., Lee, A. H., Franke, A., Glickman, J. N., Zeissig, S., Tilg, H., et al. (2008). XBP1 links ER stress to intestinal inflammation and confers genetic risk for human inflammatory bowel disease. Cell 134, 743-756. doi: 10.1016/j.cell.2008. 07.021

Kato, H., Nakajima, S., Saito, Y., Takahashi, S., Katoh, R., and Kitamura, M. (2012). mTORC1 serves ER stress-triggered apoptosis via selective activation of the IRE1JNK pathway. Cell Death Differ. 19, 310-320. doi: 10.1038/cdd.2011.98

Kawai, T., and Akira, S. (2011). Toll-like receptors and their crosstalk with other innate receptors in infection and immunity. Immunity 34, 637-650. doi: 10.1016/j.immuni.2011.05.006

Kawasaki, N., Asada, R., Saito, A., Kanemoto, S., and Imaizumi, K. (2012). Obesityinduced endoplasmic reticulum stress causes chronic inflammation in adipose tissue. Sci. Rep. 2:799. doi: 10.1038/srep00799

Kharabi Masouleh, B., Geng, H., Hurtz, C., Chan, L. N., Logan, A. C., Chang, M. S., etal. (2014). Mechanistic rationale for targeting the unfolded protein response in pre-B acute lymphoblastic leukemia. Proc. Natl. Acad. Sci. U.S.A. 111, E2219-E2228. doi: 10.1073/pnas.1400958111

Kleiner, D. E., and Brunt, E. M. (2012). Nonalcoholic fatty liver disease: pathologic patterns and biopsy evaluation in clinical research. Semin. Liver Dis. 32, 3-13. doi: $10.1055 /$ s-0032-1306421

Krausova, M., and Korinek, V. (2014). Wnt signaling in adult intestinal stem cells and cancer. Cell. Signal. 26, 570-579. doi: 10.1016/j.cellsig.2013.11.032

Kubisch, C. H., and Logsdon, C. D. (2008). Endoplasmic reticulum stress and the pancreatic acinar cell. Expert Rev. Gastroenterol. Hepatol. 2, 249-260. doi: 10.1586/17474124.2.2.249

Lake, A. D., Novak, P., Hardwick, R. N., Flores-Keown, B., Zhao, F., Klimecki, W. T., et al. (2013). The adaptive endoplasmic reticulum stress response to lipotoxicity in progressive human nonalcoholic fatty liver disease. Toxicol. Sci. 137, 26-35. doi: $10.1093 /$ toxsci/kft230

Larrain, S., and Rinella, M. E. (2012). A myriad of pathways to NASH. Clin. Liver Dis. 16, 525-548. doi: 10.1016/j.cld.2012.05.009

Lee, J. S., Mendez, R., Heng, H. H., Yang, Z. Q., and Zhang, K. (2012a). Pharmacological ER stress promotes hepatic lipogenesis and lipid droplet formation. Am. J. Transl. Res. 4, 102-113.

Lee, J. S., Zheng, Z., Mendez, R., Ha, S. W., Xie, Y., and Zhang, K. (2012b). Pharmacologic ER stress induces non-alcoholic steatohepatitis in an animal model. Toxicol. Lett. 211, 29-38. doi: 10.1016/j.toxlet.2012.02.017

Lee, M. S., Kim, M. H., and Tesh, V. L. (2013). Shiga toxins expressed by human pathogenic bacteria induce immune responses in host cells. J. Microbiol. 51, 724-730. doi: 10.1007/s12275-013-3429-3426

Leemans, J. C., Cassel, S. L., and Sutterwala, F. S. (2011). Sensing damage by the NLRP3 inflammasome. Immunol. Rev. 243, 152-162. doi: 10.1111/j.1600065X.2011.01043.x

Lerner, A. G., Upton, J. P., Praveen, P. V., Ghosh, R., Nakagawa, Y., Igbaria, A., et al. (2012). IRElalpha induces thioredoxin-interacting protein to activate the NLRP3 inflammasome and promote programmed cell death under irremediable ER stress. Cell Metab. 16, 250-264. doi: 10.1016/j.cmet.2012.07.007

Li, J., Huang, J., Li, J. S., Chen, H., Huang, K., and Zheng, L. (2012). Accumulation of endoplasmic reticulum stress and lipogenesis in the liver through generational effects of high fat diets. J. Hepatol. 56, 900-907. doi: 10.1016/j.jhep.2011. 10.018

Li, J. Q., Yu, J. T., Jiang, T., and Tan, L. (2014). Endoplasmic reticulum dysfunction in Alzheimer's disease. Mol. Neurobiol. doi: 10.1007/s12035-014-8695-8698 [Epub ahead of print].

Liu, B., and Li, Z. (2008). Endoplasmic reticulum HSP90b1 (gp96, grp94) optimizes B-cell function via chaperoning integrin and TLR but not immunoglobulin. Blood 112, 1223-1230. doi: 10.1182/blood-2008-03-143107

Liu, B., Staron, M., Hong, F., Wu, B. X., Sun, S., Morales, C., et al. (2013). Essential roles of grp94 in gut homeostasis via chaperoning canonical Wnt pathway. Proc. Natl. Acad. Sci. U.S.A. 110, 6877-6882. doi: 10.1073/pnas.1302933110

Liu, M., and Dudley, S. C. Jr. (2014). Targeting the unfolded protein response in heart diseases. Expert Opin. Ther. Targets 18, 719-723. doi: $10.1517 / 14728222.2014 .918605$

Logue, S. E., Cleary, P., Saveljeva, S., and Samali, A. (2013). New directions in ER stress-induced cell death. Apoptosis 18, 537-546. doi: 10.1007/s10495-013-0818816

Machado, M. V., and Cortez-Pinto, H. (2012). Gut microbiota and nonalcoholic fatty liver disease. Ann. Hepatol. 11, 440-449.
Mahadevan, N. R., Rodvold, J., Sepulveda, H., Rossi, S., Drew, A. F., and Zanetti, M. (2011). Transmission of endoplasmic reticulum stress and pro-inflammation from tumor cells to myeloid cells. Proc. Natl. Acad. Sci. U.S.A. 108, 6561-6566. doi: $10.1073 /$ pnas. 1008942108

Mahoney, E., Maddocks, K., Flynn, J., Jones, J., Cole, S. L., Zhang, X., et al. (2013). Identification of endoplasmic reticulum stress-inducing agents by antagonizing autophagy: a new potential strategy for identification of anti-cancer therapeutics in B-cell malignancies. Leuk. Lymphoma 54, 2685-2692. doi: $10.3109 / 10428194.2013 .781168$

Malhi, H., and Kaufman, R. J. (2011). Endoplasmic reticulum stress in liver disease. J. Hepatol. 54, 795-809. doi: 10.1016/j.jhep.2010.11.005

Martinon, F., Chen, X., Lee, A. H., and Glimcher, L. H. (2010). TLR activation of the transcription factor XBP1 regulates innate immune responses in macrophages. Nat. Immunol. 11, 411-418. doi: 10.1038/ni.1857

Martin-Perez, R., Palacios, C., Yerbes, R., Cano-Gonzalez, A., Iglesias-Serret, D., Gil, J., et al. (2014). Activated ERBB2/HER2 licenses sensitivity to apoptosis upon endoplasmic reticulum stress through a PERK-dependent pathway. Cancer Res. 74, 1766-1777. doi: 10.1158/0008-5472.CAN-13-1747

McAlpine, C. S., Bowes, A. J., and Werstuck, G. H. (2010). Diabetes, hyperglycemia and accelerated atherosclerosis: evidence supporting a role for endoplasmic reticulum (ER) stress signaling. Cardiovasc. Hematol. Disord. Drug Targets 10, 151-157. doi: 10.2174/187152910791292529

McAlpine, C. S., and Werstuck, G. H. (2013). The development and progression of atherosclerosis: evidence supporting a role for endoplasmic reticulum (ER) stress signaling. Cardiovasc. Hematol. Disord. Drug Targets 13, 158-164.

McGuckin, M. A., Eri, R. D., Das, I., Lourie, R., and Florin, T. H. (2010). ER stress and the unfolded protein response in intestinal inflammation. Am. J. Physiol. Gastrointest. Liver Physiol. 298, G820-G832. doi: 10.1152/ajpgi. 00063.2010

McMahon, J. M., Mcquaid, S., Reynolds, R., and Fitzgerald, U. F. (2012). Increased expression of ER stress- and hypoxia-associated molecules in grey matter lesions in multiple sclerosis. Mult. Scler. 18, 1437-1447. doi: 10.1177/1352458512438455

Menu, P., Mayor, A., Zhou, R., Tardivel, A., Ichijo, H., Mori, K., et al. (2012). ER stress activates the NLRP3 inflammasome via an UPR-independent pathway. Cell Death Dis. 3:e261. doi: 10.1038/cddis.2011.132

Menu, P., and Vince, J. E. (2011). The NLRP3 inflammasome in health and disease: the good, the bad and the ugly. Clin. Exp. Immunol. 166, 1-15. doi: 10.1111/j.13652249.2011.04440.x

Mercado, G., Valdes, P., and Hetz, C. (2013). An ERcentric view of Parkinson's disease. Trends Mol. Med. 19, 165-175. doi: 10.1016/j.molmed.2012.12.005

Merquiol, E., Uzi, D., Mueller, T., Goldenberg, D., Nahmias, Y., Xavier, R. J., et al. (2011). HCV causes chronic endoplasmic reticulum stress leading to adaptation and interference with the unfolded protein response. PLOS ONE 6:e24660. doi: 10.1371/journal.pone.0024660

Milic, S., and Stimac, D. (2012). Nonalcoholic fatty liver disease/steatohepatitis: epidemiology, pathogenesis, clinical presentation and treatment. Dig. Dis. 30, 158-162. doi: 10.1159/000336669

Morales, C., Rachidi, S., Hong, F., Sun, S., Ouyang, X., Wallace, C., et al. (2014). Immune chaperone gp96 drives the contributions of macrophages to inflammatory colon tumorigenesis. Cancer Res. 74, 446-459. doi: 10.1158/00085472.CAN-13-1677

Muralidharan, S., and Mandrekar, P. (2013). Cellular stress response and innate immune signaling: integrating pathways in host defense and inflammation. J. Leukoc. Biol. 94, 1167-1184. doi: 10.1189/jlb.0313153

Nagarajan, P., Mahesh Kumar, M. J., Venkatesan, R., Majundar, S. S., and Juyal, R. C. (2012). Genetically modified mouse models for the study of nonalcoholic fatty liver disease. World J. Gastroenterol. 18, 1141-1153. doi: 10.3748/wjg.v18.i11.1141

Nakajima, S., Hiramatsu, N., Hayakawa, K., Saito, Y., Kato, H., Huang, T., et al. (2011). Selective abrogation of BiP/GRP78 blunts activation of NF-kappaB through the ATF6 branch of the UPR: involvement of C/EBPbeta and mTORdependent dephosphorylation of Akt. Mol. Cell. Biol. 31, 1710-1718. doi: 10.1128/MCB.00939-910

Nishitoh, H. (2012). CHOP is a multifunctional transcription factor in the ER stress response. J. Biochem. 151, 217-219. doi: 10.1093/jb/mvr143

Oganesyan, G., Saha, S. K., Guo, B., He, J. Q., Shahangian, A., Zarnegar, B., et al. (2006). Critical role of TRAF3 in the Toll-like receptor-dependent and -independent antiviral response. Nature 439, 208-211. doi: 10.1038/nature04374 
Oikawa, D., Kitamura, A., Kinjo, M., and Iwawaki, T. (2012). Direct association of unfolded proteins with mammalian ER stress sensor, IRE1beta. PLoS ONE 7:e51290. doi: 10.1371/journal.pone.0051290

Okazaki, T., Wang, M. H., Rawsthorne, P., Sargent, M., Datta, L. W., Shugart, Y. Y., et al. (2008). Contributions of IBD5, IL23R, ATG16L1, and NOD2 to Crohn's disease risk in a population-based case-control study: evidence of gene-gene interactions. Inflamm. Bowel Dis. 14, 1528-1541. doi: 10.1002/ibd.20512

Oslowski, C. M., Hara, T., O’sullivan-Murphy, B., Kanekura, K., Lu, S., Hara, M. et al. (2012). Thioredoxin-interacting protein mediates ER stress-induced beta cell death through initiation of the inflammasome. Cell Metab. 16, 265-273. doi: 10.1016/j.cmet.2012.07.005

Osorio, F., Tavernier, S. J., Hoffmann, E., Saeys, Y., Martens, L., Vetters, J., et al. (2014). The unfolded-protein-response sensor IRE-1alpha regulates the function of CD8alpha+ dendritic cells. Nat. Immunol. 15, 248-257. doi: 10.1038/ni.2808

Ozcan, U., Yilmaz, E., Ozcan, L., Furuhashi, M., Vaillancourt, E., Smith, R. O., et al. (2006). Chemical chaperones reduce ER stress and restore glucose homeostasis in a mouse model of type 2 diabetes. Science 313, 1137-1140. doi $10.1126 /$ science. 1128294

Pagliassotti, M. J. (2012). Endoplasmic reticulum stress in nonalcoholic fatty liver disease. Annu. Rev. Nutr. 32, 17-33. doi: 10.1146/annurev-nutr-071811-150644

Papa, F. R. (2012). Endoplasmic reticulum stress, pancreatic beta-cell degeneration, and diabetes. Cold Spring Harb. Perspect. Med. 2:a007666. doi: $10.1101 /$ cshperspect.a007666

Papatriantafyllou, M. (2011). Mucosal immunology: inflammasome shapes the microbiota. Nat. Rev. Immunol. 11, 439. doi: 10.1038/nri3012

Petrasek, J., Bala, S., Csak, T., Lippai, D., Kodys, K., Menashy, V., et al. (2012). IL-1 receptor antagonist ameliorates inflammasome-dependent alcoholic steatohepatitis in mice. J. Clin. Invest. 122, 3476-3489. doi: 10.1172/JCI60777

Pfaffenbach, K. T., and Lee, A. S. (2011). The critical role of GRP78 in physiologic and pathologic stress. Curr. Opin. Cell Biol. 23, 150-156. doi: 10.1016/j.ceb.2010.09.007

Pincus, D., Chevalier, M. W., Aragon, T., Van Anken, E., Vidal, S. E., El-Samad, H., et al. (2010). BiP binding to the ER-stress sensor Irel tunes the homeostatic behavior of the unfolded protein response. PLoS Biol. 8:e1000415. doi: 10.1371/journal.pbio. 1000415

Pineda, G., Ea, C. K., and Chen, Z. J. (2007). Ubiquitination and TRAF signaling. Adv. Exp. Med. Biol. 597, 80-92. doi: 10.1007/978-0-387-70630-6_7

Qiu, Q., Zheng, Z., Chang, L., Zhao, Y. S., Tan, C., Dandekar, A., et al. (2013). Toll-like receptor-mediated IRElalpha activation as a therapeutic target for inflammatory arthritis. EMBO J. 32, 2477-2490. doi: 10.1038/emboj.2013.183

Rathinam, V. A., Vanaja, S. K., and Fitzgerald, K. A. (2012). Regulation of inflammasome signaling. Nat. Immunol. 13, 333-332. doi: 10.1038/ni.2237

Razani, B., and Cheng, G. (2010). NF-kappaB: much learned, much to learn. Sci. Signal. 3:pe29. doi: 10.1126/scisignal.3138pe29

Romero-Ramirez, L., Cao, H., Regalado, M. P., Kambham, N., Siemann, D., Kim, J. J., et al. (2009). X box-binding protein 1 regulates angiogenesis in human pancreatic adenocarcinomas. Transl. Oncol. 2, 31-38. doi: 10.1593/tlo.08211

Sands, B. E. (2007). Inflammatory bowel disease: past, present, and future. $J$ Gastroenterol. 42, 16-25. doi: 10.1007/s00535-006-1995-1997

Sarra, M., Pallone, F., Macdonald, T. T., and Monteleone, G. (2010). IL-23/IL-17 axis in IBD. Inflamm. Bowel Dis. 16, 1808-1813. doi: 10.1002/ibd.21248

Savic, S., Ouboussad, L., Dickie, L. J., Geiler, J., Wong, C., Doody, G. M., et al. (2014). TLR dependent XBP-1 activation induces an autocrine loop in rheumatoid arthritis synoviocytes. J. Autoimmun. 50, 59-66. doi: 10.1016/j.jaut.2013. 11.002

Schroder, M., and Sutcliffe, L. (2010). Consequences of stress in the secretory pathway: the ER stress response and its role in the metabolic syndrome. Methods Mol. Biol. 648, 43-62. doi: 10.1007/978-1-60761-756-3_3

Senftleben, U., and Karin, M. (2002). The IKK/NF-kappa B pathway. Crit. Care Med. 30, S18-S26. doi: 10.1097/00003246-200201001-00003

Sha, H., He, Y., Yang, L., and Qi, L. (2011). Stressed out about obesity: IRE1alphaXBP1 in metabolic disorders. Trends Endocrinol. Metab. 22, 374-381. doi: 10.1016/j.tem.2011.05.002

Shenderov, K., Riteau, N., Yip, R., Mayer-Barber, K. D., Oland, S., Hieny, S., et al. (2014). Cutting edge: endoplasmic reticulum stress licenses macrophages to produce mature IL-1beta in response to TLR4 stimulation through a caspase-8- and TRIF-dependent pathway. J. Immunol. 192, 2029-2033. doi: 10.4049/jimmunol.1302549
Shimodaira, Y., Takahashi, S., Kinouchi, Y., Endo, K., Shiga, H., Kakuta, Y., et al. (2014). Modulation of endoplasmic reticulum (ER) stress-induced autophagy by $\mathrm{C} / \mathrm{EBP}$ homologous protein (CHOP) and inositol-requiring enzyme lalpha (IRElalpha) in human colon cancer cells. Biochem. Biophys. Res. Commun. 445, 524-533. doi: 10.1016/j.bbrc.2014.02.054

Shuda, M., Kondoh, N., Imazeki, N., Tanaka, K., Okada, T., Mori, K., et al. (2003). Activation of the ATF6, XBP1 and grp78 genes in human hepatocellular carcinoma: a possible involvement of the ER stress pathway in hepatocarcinogenesis. J. Hepatol. 38, 605-614. doi: 10.1016/S0168-8278(03)00029-1

Smith, J. A. (2014). A new paradigm: innate immune sensing of viruses via the unfolded protein response. Front. Microbiol. 5:222. doi: 10.3389/fmicb.2014.00222

Staron, M., Yang, Y., Liu, B., Li, J., Shen, Y., Zuniga-Pflucker, J. C., et al. (2010). gp96, an endoplasmic reticulum master chaperone for integrins and Toll-like receptors, selectively regulates early $\mathrm{T}$ and B lymphopoiesis. Blood 115, 2380-2390. doi: 10.1182/blood-2009-07-233031

Stienstra, R., Van Diepen, J. A., Tack, C. J., Zaki, M. H., Van De Veerdonk, F. L., Perera, D., et al. (2011). Inflammasome is a central player in the induction of obesity and insulin resistance. Proc. Natl. Acad. Sci. U.S.A. 108, 15324-15329. doi: 10.1073/pnas. 1100255108

Strober, W., Fuss, I., and Mannon, P. (2007). The fundamental basis of inflammatory bowel disease. J. Clin. Invest. 117, 514-521. doi: 10.1172/JCI30587

Szabo, G., and Csak, T. (2012). Inflammasomes in liver diseases. J. Hepatol. 57, 642-654. doi: 10.1016/j.jhep.2012.03.035

Takeuchi, O., and Akira, S. (2010). Pattern recognition receptors and inflammation. Cell 140, 805-820. doi: 10.1016/j.cell.2010.01.022

Tam, A. B., Mercado, E. L., Hoffmann, A., and Niwa, M. (2012). ER stress activates NF-kappaB by integrating functions of basal IKK activity, IRE1 and PERK. PLoS ONE 7:e45078. doi: 10.1371/journal.pone.0045078

Tang, J., Guo, Y. S., Zhang, Y., Yu, X. L., Li, L., Huang, W., et al. (2012). CD147 induces UPR to inhibit apoptosis and chemosensitivity by increasing the transcription of Bip in hepatocellular carcinoma. Cell Death Differ. 19, 1779-1790. doi: $10.1038 /$ cdd. 2012.60

Tesh, V. L. (2012). Activation of cell stress response pathways by Shiga toxins. Cell Microbiol. 14, 1-9. doi: 10.1111/j.1462-5822.2011.01684.x

Ting, J. P., Duncan, J. A., and Lei, Y. (2010). How the noninflammasome NLRs function in the innate immune system. Science 327, 286-290. doi: 10.1126/science. 1184004

Tripathi, Y. B., and Pandey, V. (2012). Obesity and endoplasmic reticulum (ER) stresses. Front. Immunol. 3:240. doi: 10.3389/fimmu.2012.00240

Tuyama, A. C., and Chang, C. Y. (2012). Non-alcoholic fatty liver disease. J. Diabetes 4, 266-280. doi: 10.1111/j.1753-0407.2012.00204.x

Upton, J. P., Wang, L., Han, D., Wang, E. S., Huskey, N. E., Lim, L., et al. (2012). IRElalpha cleaves select microRNAs during ER stress to derepress translation of proapoptotic Caspase-2. Science 338, 818-822. doi: 10.1126/science. 1226191

Urano, F., Wang, X., Bertolotti, A., Zhang, Y., Chung, P., Harding, H. P., et al. (2000). Coupling of stress in the ER to activation of JNK protein kinases by transmembrane protein kinase IRE1. Science 287, 664-666. doi: 10.1126/science.287.5453.664

Vandanmagsar, B., Youm, Y. H., Ravussin, A., Galgani, J. E., Stadler, K., Mynatt, R. L., etal. (2011). The NLRP3 inflammasome instigates obesity-induced inflammation and insulin resistance. Nat. Med. 17, 179-188. doi: 10.1038/ nm.2279

Van Limbergen, J., Russell, R. K., Nimmo, E. R., and Satsangi, J. (2007). The genetics of inflammatory bowel disease. Am. J. Gastroenterol. 102, 2820-2831. doi: 10.1111/j.1572-0241.2007.01527.x

Vidal, R. L., Figueroa, A., Court, F. A., Thielen, P., Molina, C., Wirth, C., et al. (2012). Targeting the UPR transcription factor XBP1 protects against Huntington's disease through the regulation of FoxO1 and autophagy. Hum. Mol. Genet. 21, 2245-2262. doi: 10.1093/hmg/dds040

Wen, H., Ting, J. P., and O'Neill, L. A. (2012). A role for the NLRP3 inflammasome in metabolic diseases - did Warburg miss inflammation? Nat. Immunol. 13, 352-357. doi: 10.1038/ni.2228

Wierzbicki, A. S., and Oben, J. (2012). Nonalcoholic fatty liver disease and lipids. Curr. Opin. Lipidol. 23, 345-352. doi: 10.1097/MOL.0b013e3283541cfc

Woo, C. W., Cui, D., Arellano, J., Dorweiler, B., Harding, H., Fitzgerald, K. A., et al. (2009). Adaptive suppression of the ATF4-CHOP branch of the unfolded 
protein response by toll-like receptor signalling. Nat. Cell Biol. 11, 1473-1480. doi: $10.1038 /$ ncb1996

Woo, C. W., Kutzler, L., Kimball, S. R., and Tabas, I. (2012). Toll-like receptor activation suppresses ER stress factor CHOP and translation inhibition through activation of eIF2B. Nat. Cell Biol. 14, 192-200. doi: 10.1038/ncb2408

Wood, N. J. (2012). Microbiota: dysbiosis driven by inflammasome deficiency exacerbates hepatic steatosis and governs rate of NAFLD progression. Nat. Rev Gastroenterol. Hepatol. 9, 123. doi: 10.1038/nrgastro.2012.21

Yamazaki, H., Hiramatsu, N., Hayakawa, K., Tagawa, Y., Okamura, M., Ogata, R., et al. (2009). Activation of the Akt-NF-kappaB pathway by subtilase cytotoxin through the ATF6 branch of the unfolded protein response. J. Immunol. 183, 1480-1487. doi: 10.4049/jimmunol.0900017

Yang, L., Li, P., Fu, S., Calay, E. S., and Hotamisligil, G. S. (2010). Defective hepatic autophagy in obesity promotes ER stress and causes insulin resistance. Cell Metab. 11, 467-478. doi: 10.1016/j.cmet.2010.04.005

Yang, Y., and Li, Z. (2005). Roles of heat shock protein gp96 in the ER quality control: redundant or unique function? Mol. Cells 20, 173-182.

Yang, Y., Liu, B., Dai, J., Srivastava, P. K., Zammit, D. J., Lefrancois, L., et al. (2007). Heat shock protein gp96 is a master chaperone for toll-like receptors and is important in the innate function of macrophages. Immunity 26, 215-226. doi: 10.1016/j.immuni.2006.12.005

Ye, R., Jung, D. Y., Jun, J. Y., Li, J., Luo, S., Ko, H. J., et al. (2010). Grp78 heterozygosity promotes adaptive unfolded protein response and attenuates diet-induced obesity and insulin resistance. Diabetes Metab. Res. Rev. 59, 6-16. doi: 10.2337/ db09-0755

Yoo, S. A., You, S., Yoon, H. J., Kim, D. H., Kim, H. S., Lee, K., et al. (2012). A novel pathogenic role of the ER chaperone GRP78/BiP in rheumatoid arthritis. J. Exp. Med. 209, 871-886. doi: 10.1084/jem.20111783

Zaki, M. H., Boyd, K. L., Vogel, P., Kastan, M. B., Lamkanfi, M., and Kanneganti, T. D. (2010). The NLRP3 inflammasome protects against loss of epithelial integrity and mortality during experimental colitis. Immunity 32, 379-391. doi: 10.1016/j.immuni.2010.03.003

Zha, B. S., and Zhou, H. (2012). ER stress and lipid metabolism in adipocytes. Biochem. Res. Int. 2012, 312943. doi: 10.1155/2012/312943
Zhang, J., Fu, S., Sun, S., Li, Z., and Guo, B. (2014). Inflammasome activation has an important role in the development of spontaneous colitis. Mucosal. Immunol. doi: 10.1038/mi.2014.1 [Epub ahead of print].

Zhang, K., Wang, S., Malhotra, J., Hassler, J. R., Back, S. H., Wang, G., et al. (2011). The unfolded protein response transducer IRE1alpha prevents ER stress-induced hepatic steatosis. EMBO J. 30, 1357-1375. doi: 10.1038/emboj. 2011.52

Zheng, Y. Z., Cao, Z. G., Hu, X., and Shao, Z. M. (2014). The endoplasmic reticulum stress markers GRP78 and CHOP predict disease-free survival and responsiveness to chemotherapy in breast cancer. Breast Cancer Res. Treat. 145, 349-358. doi: $10.1007 /$ s10549-014-2967-x

Zhou, A. X., and Tabas, I. (2013). The UPR in atherosclerosis. Semin. Immunopathol. 35, 321-332. doi: 10.1007/s00281-013-0372-x

Zhou, H., and Liu, R. (2014). ER stress and hepatic lipid metabolism. Front. Genet. 5:112. doi: 10.3389/fgene.2014.00112

Zhou, L., and Liu, F. (2010). Autophagy: roles in obesity-induced ER stress and adiponectin downregulation in adipocytes. Autophagy 6, 1196-1197. doi: 10.4161/auto.6.8.13478

Conflict of Interest Statement: The authors declare that the research was conducted in the absence of any commercial or financial relationships that could be construed as a potential conflict of interest.

Received: 19 May 2014; accepted: 07 July 2014; published online: 25 July 2014. Citation: Guo B and Li Z (2014) Endoplasmic reticulum stress in hepatic steatosis and inflammatory bowel diseases. Front. Genet. 5:242. doi: 10.3389/fgene.2014.00242

This article was submitted to Genomic Endocrinology, a section of the journal Frontiers in Genetics.

Copyright (C) 2014 Guo and Li. This is an open-access article distributed under the terms of the Creative Commons Attribution License (CC BY). The use, distribution or reproduction in other forums is permitted, provided the original author(s) or licensor are credited and that the original publication in this journal is cited, in accordance with accepted academic practice. No use, distribution or reproduction is permitted which does not comply with these terms. 